\title{
BMJ Open Healthcare under siege: a qualitative study of health-worker responses to targeting and besiegement in Syria
}

\author{
Nasser Fardousi, ${ }^{1,2}$ Yazan Douedari, ${ }^{2}$ Natasha Howard ${ }^{2,3}$
}

To cite: Fardousi N, Douedari Y, Howard N. Healthcare under siege: a qualitative study of health-worker responses to targeting and besiegement in Syria. BMJ Open 2019;9:e029651. doi:10.1136/ bmjopen-2019-029651

- Prepublication history for this paper is available online. To view these files, please visit the journal online (http://dx.doi org/10.1136/bmjopen-2019029651).

Received 04 February 2019 Revised 31 May 2019 Accepted 30 July 2019
Check for updates

(C) Author(s) (or their employer(s)) 2019. Re-use permitted under CC BY-NC. No commercial re-use. See rights and permissions. Published by BMJ.

${ }^{1}$ Department of Health Management and Policy, Faculty of Health Sciences, American University of Beirut, Beirut, Lebanon

${ }^{2}$ Department of Global Health and Development, Faculty of Public Health and Policy, London School of Hygiene and Tropical Medicine, London, UK

${ }^{3}$ Saw Swee Hock School of Public Health, National University of Singapore, Singapore, Singapore

Correspondence to

Nasser Fardousi;

Ics-fardousi@aub.edu.lb

\section{ABSTRACT}

Objectives To explore health-worker perspectives on security, improving safety, managing constrained resources and handling mass casualties during besiegement in Syria.

Design A qualitative study using semi-structured key informant interviews, conducted remotely over WhatsApp and Skype, and analysed thematically using inductive coding.

Setting Secondary and tertiary health facilities affected by besiegement in Aleppo (from July to December 2016) and Rural Damascus (from August 2013 to February 2018).

Participants Twenty-one male Syrian health-workers and service-users who had experienced besiegement and targeting of their health facilities.

Results Participants described four related challenges of: (i) conflict-related responses, particularly responding to mass casualties; (ii) targeted attack responses, particularly preventing/surviving facility bombings; (iii) besiegement responses, particularly mitigating severe resource constraints; and (iv) chronic risk responses, particularly maintaining emotional resilience. Mass casualty response involved triage and training to prioritise mortality reduction and available resources, for example those with greatest need and likelihood of survival. Targeting response was largely physical, including fortification, working underground, reducing visibility and services dispersal. Besiegement response required resource conservation, for example, controlling consumption, reusing consumables, low-technology equipment, finding alternative supply routes, stockpiling and strengthening available human resources through online trainings and establishing a medical school in Ghouta. Risk responses included managing safety worries, finding value in work and maintaining hope.

Conclusion Besieged health-workers were most affected by severe resource constraints and safety concerns while responding to overwhelming mass casualty events. Lessons for targeting/besiegement planning include training staff and preparing for: (i) mass casualties, through local/online health-worker training in triage, emergency response and resource conservation; allowing task-shifting; and providing access to low-technology equipment; (ii) attacks, through strengthened facility security, for example, protection and deterrence through fortification, working underground and reducing visibility; and (iii) besiegement, through ensuring access to internet, electricity and low-technology/reusable equipment;

\section{Strengths and limitations of this study}

This study uniquely explores initial efforts of service managers and frontline health-workers to respond to and mitigate the targeting and besiegement of their health facilities during the ongoing conflict in Syria.

- Two co-authors are Syrian health-workers who have provided health services in opposition-controlled Syria and have first-hand understanding of the challenges facing Syria's frontline health professionals.

- Due to limited empirical research on frontline health-worker experiences in Syria, findings have implications for the global humanitarian community to provide greater support to frontline Syrian health professionals, through appropriate supplies and training and helping to end the targeting and besiegement that violate international humanitarian law.

This is an exploratory study of a small sample of health-workers working in opposition-controlled regions of Syria.

securely stockpiling fuel, medicines and supplies; and establishing alternative supply routes.

\section{INTRODUCTION}

Syria is a lower-middle income country, with a population of over 23 million in 2004, ${ }^{12}$ reduced to an estimated 16.9 million in $2018 .^{3}$ The Syrian revolution began in March 2011, as security forces arresting teenagers in Daraa for painting anti-President Assad slogans on school walls triggered nationwide protests. ${ }^{4}$ Protests against the government, for perceived lack of freedoms and authoritarianism, were responded to forcefully ${ }^{5}$ with many reported detained, killed or tortured. ${ }^{6}$ Civilians began arming themselves ${ }^{4}$ and violence spread, creating a massive humanitarian crisis. The Syrian conflict enters its eighth year with an unknown number dead (364 792 deaths documented ${ }^{7}$ ), 6.3 million internally displaced and 6 million refugees in neighbouring countries. ${ }^{8}$ 
The four 1949 Geneva Conventions obliged ratifying states to refrain from violence against those people not participating in combat. ${ }^{9}$ Ratified by 196 countries, including Syria, they require all parties to protect and ensure safety of health facilities, personnel, wounded civilians and wounded combatants. ${ }^{10}$ Attacks on healthcare have been reported in Afghanistan, Iraq, the Democratic Republic of Congo and Sierra Leone ${ }^{11}{ }^{12}$ but have been 'exceptionally egregious' in Syria. ${ }^{13} 14$ For example, Physicians for Human Rights reported at least 542 attacks on 348 health facilities between March 2011 and September $2018,{ }^{15} 490$ committed by the Syrian Government and its allies. ${ }^{16}$ In the first half of 2017 , at least 36 attacks against healthcare were verified. ${ }^{17}$ Aleppo governorate alone experienced attacks against $63 \%$ of its hospitals. ${ }^{18-20}$ Since attacks happened in rapid succession and increased with military operations in opposition-controlled areas, many actors considered health facility attacks as deliberate targeting. ${ }^{1421}$

'Siege' is defined as 'a military operation in which enemy forces surround a town or building, cutting off essential supplies, with the aim of compelling those inside to surrender'. ${ }^{22}$ This 'kneel or starve' strategy was used to force communities in opposition-controlled areas to surrender, ${ }^{23}$ and primarily used by pro-government forces in Syria. ${ }^{24}$ The United Nations Office for the Coordination of Humanitarian Affairs (UNOCHA) defines besieged areas in Syria as: 'surrounded by armed actors with the sustained effect that humanitarian assistance cannot regularly enter, and civilians, the sick and wounded cannot regularly exit...'. In November 2016, UNOCHA recognised approximately 0.97 million people in besieged areas (figure 1) and 3.9 million in hardto-reach areas. The Syrian Government and its allies were responsible for approximately $88 \%$ of community besiegement, among approximately 880000 Syrians experiencing siege, while $10 \%$ were besieged by other armed groups and $2 \%$ by opposition groups. ${ }^{24}$

Aleppo and Ghouta both experienced siege. Aleppo is Syria's largest city and capital of its most-populated governorate. ${ }^{225}$ Battles for its control continued from 2012 until December 2016, when pro-government forces reclaimed control over the whole city. ${ }^{26-36}$ Rural Damascus, with an estimated pre-conflict population of two million, ${ }^{25} 3738$ hosted some of the strongest and earliest anti-government protests in Ghouta. ${ }^{37}$ The Eastern Aleppo siege was characterised by an acute and heavy military offensive (July-December 2016), while the siege of Ghouta

\section{Syrian Arab Republic: Besieged communities (as at 18 Nov 2016)}

\section{(9) OCHA}

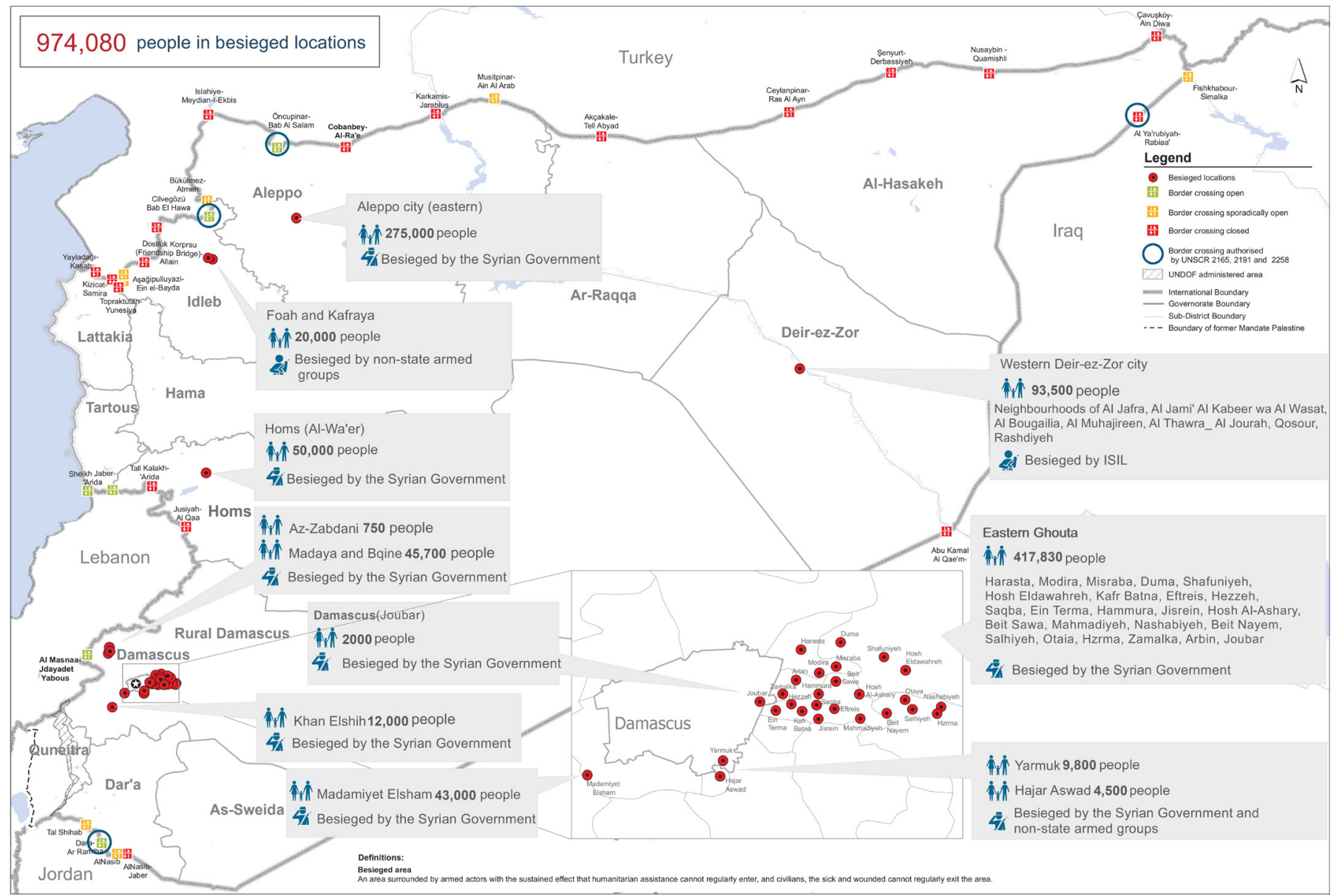

Figure 1 Besieged communities in Syria, November 2016. Source: UNOCHA. Besieged communities, as of November 2016. https://reliefweb.int/map/syrian-arab-republic/syrian-arab-republic-besieged-communities-18-november-2016. 
(2013-2018) was protracted with relatively less intensive military activity.

Health facility attacks and besiegement have severely damaged the Syrian health system. Médecins Sans Frontières reported the insecure conditions within which Syrian health-workers operated, including lack of human resources, hospital beds, fuel and medicines. ${ }^{39}$ This contributed to disease outbreaks $\left(\mathrm{eg}\right.$, polio ${ }^{40}$ ), dangerous shortages of qualified health-workers-particularly doctors, ${ }^{13} 16$ and remaining facilities overloaded with injured patients. Women increasingly chose caesarean sections to control time and location of delivery, while elective healthcare dropped severely. The World Bank and others highlighted that most deaths in Syria were caused by health system breakdown rather than fighting. ${ }^{40}$

This study aimed to explore experiences and coping strategies of health-workers and service-users during the sieges of Aleppo (June-December 2016) and Ghouta (2013-2018). Objectives were to: (i) identify strategies used to mitigate healthcare besiegement and lack of resources; and (ii) examine their experiences and perceptions of these challenges during acute and protracted sieges.

\section{METHODS}

\section{Study design and sampling}

We selected a qualitative study design, using semi-structured key informant interviews with health-workers and service-users who experienced siege in Aleppo in 2016 or Ghouta in 2013-2017. The primary research question was: 'What are the main challenges and adaptive approaches for administrators and frontline health-workers in besieged and targeted health facilities in Syria?'

We initially used purposive sampling, to include participants who provided healthcare, or had sought healthcare, in a besieged area with no access to aid either by land or air routes. Recruitment was challenged by confidentiality and safety concerns, limited electricity/internet access and time constraints. Personal contacts were thus snowballed using WhatsApp and Skype, with each recommending 2-3 other potential participants, to increase trust and willingness to participate. Interviewers were male Syrian health professionals, trained in qualitative methods, and conducting research as part of their MSc studies. Thus, positioning and reflexivity influenced interviewing and analysis. Identifying the common connection who recommended the interviewee increased comfort with participating. While we did not ask for participants' names, many disclosed this and details of their job as they indicated their names were already known on media, while others used code names. Participants viewed the research and interviewer role differently. Prior to the interviews, many questioned the nature of interviews, the organisation interviewers belonged to and whether they were journalists. However, most indicated participation might raise awareness of their situation and potentially help others. One refused to participate, as he had already 'talked a lot, but all in vain', suggesting frustration at the international community's lack of response.

\section{Data collection and analysis}

We developed two topic guides to examine health-worker and service-user perceptions and experiences, based on personal experience in Syria, expert consultation and the literature. ${ }^{24} 39{ }^{41-43}$ Guides were piloted prior to use. Topics included maintaining security, resource management and practice adaptations. NF and YD conducted semi-structured interviews in Syrian Arabic, recorded them using Windows audio recorder, then transcribed/ translated and transferred transcripts to Nvivo V.9 for analysis with field notes used for triangulation. We continued interviews until no new themes emerged. We used WhatsApp or Skype call functions as face-to-face and phone interviews were prohibitively difficult in opposition-controlled areas. We recorded written and verbal informed consent before interviews. We sent participants electronic copies of information sheet and consent forms, with questions answered before interviews. Participants used mobile phones to photograph and send signed consent forms. Given security concerns, interviews were recorded anonymously using identification codes. Where possible, participants were sent their anonymised transcripts via encrypted institutional emails for further comment/correction, and were asked for feedback on initial themes. Recordings and transcripts were stored in password-protected files.

NF and YD analysed data thematically in Arabic, using inductive coding according to Braun and Clarke's six steps. ${ }^{445}$ Each coded half of total transcripts and shared analysis, with $\mathrm{NH}$ checking consistency of coding and analysis. Analysis began during data collection, to help determine when saturation was reached. To minimise loss through translation, only codes, themes and quotes were double-translated into English by two bilingual speakers to improve reliability. Codes and themes were reviewed by $\mathrm{NH}$ and discrepancies agreed between authors. Reporting adheres to the Consolidated Criteria for Reporting Qualitative research (COREQ). ${ }^{45}$

\section{Ethics}

No formal ethics committee or internationally recognised government institutions operated in opposition-controlled areas in Syria at the time of research. Research conforms to Declaration of Helsinki principles.

\section{Patient and public involvement}

No patients or members of the public were involved in conducting this research.

\section{RESULTS}

\section{Participant characteristics and themes}

Table 1 shows 21 participating health-workers and serviceusers (ie, 10 in Aleppo, 5 in Rural Damascus, and 6 in other high-risk opposition-controlled districts affected by 


\begin{tabular}{|c|c|c|c|}
\hline Code & Category & Location & Interview \\
\hline AA1 & Administrator & Aleppo & Whatsapp \\
\hline SA2 & Surgeon & Aleppo & Whatsapp \\
\hline PA3 & Pharmacist & Aleppo & Whatsapp \\
\hline NA4 & Neuro resident & Aleppo & Whatsapp \\
\hline EA5 & Emergency doctor & Aleppo & Whatsapp \\
\hline RA6 & Nurse & Aleppo & Whatsapp \\
\hline DA7 & Dentist & Aleppo & Whatsapp \\
\hline TA8 & Doctor assistant & Aleppo & Whatsapp \\
\hline HD5 & $\begin{array}{l}\text { Health directorate } \\
\text { staff }\end{array}$ & Aleppo & Skype \\
\hline SU1 & Service-user & Aleppo & Skype \\
\hline MG1 & Medical student & $\begin{array}{l}\text { Ghouta/Rural } \\
\text { Damascus }\end{array}$ & Whatsapp \\
\hline MG2 & Medical student & $\begin{array}{l}\text { Ghouta/Rural } \\
\text { Damascus }\end{array}$ & Whatsapp \\
\hline SG3 & Surgeon & $\begin{array}{l}\text { Ghouta/Rural } \\
\text { Damascus }\end{array}$ & Whatsapp \\
\hline HD4 & $\begin{array}{l}\text { Health directorate } \\
\text { staff }\end{array}$ & $\begin{array}{l}\text { Ghouta/Rural } \\
\text { Damascus }\end{array}$ & Skype \\
\hline SU4 & Service-user & $\begin{array}{l}\text { Ghouta/Rural } \\
\text { Damascus }\end{array}$ & Whatsapp \\
\hline HD1 & $\begin{array}{l}\text { Health directorate } \\
\text { staff }\end{array}$ & Idleb & Whatsapp \\
\hline HD2 & $\begin{array}{l}\text { Health directorate } \\
\text { staff }\end{array}$ & Hama & Whatsapp \\
\hline HD3 & $\begin{array}{l}\text { Health directorate } \\
\text { staff }\end{array}$ & Dara'a & Whatsapp \\
\hline SU2 & Service-user & Idleb & Whatsapp \\
\hline SU3 & Service-user & Dara'a & Whatsapp \\
\hline SU5 & Service-user & Hama & Whatsapp \\
\hline
\end{tabular}

aspects of besiegement), interviewed during 2016-2017, who had experienced health facility targeting and/or besiegement.

Table 2 shows results framed under four overarching themes of: (i) conflict-related responses, particularly to mass casualties; (ii) targeted attack responses, particularly to facility bombings; (iii) besiegement responses, particularly to severe resource constraints; and (iv) perceived risk responses, particularly to stress and safety concerns.

\section{Conflict-related responses}

Severe security and resource restrictions-particularly influxes of mass casualties-required altering treatment standards to prioritise mortality reduction over service quality, including triage, sterilisation, transfusion and X-rays.

The quality of services are bad $[\ldots]$ there is absence of basic needs in field hospitals [...] However, considering the support they receive, I would say [...service quality] is excellent. SU3
Triage

The triage process was new to most, as only emergency doctors were trained to use it prior to the conflict, and participants were quick to note its value for all healthworkers faced with the new reality of frequent mass casualty events.

Sometimes, within half an hour, hospitals receive 500-1000 injured people SU4

Participants described the benefits of the triage process in mitigating the stresses and ethical quandaries of prioritising evacuation of casualties from strike zones to field hospitals via ambulance, emergency department triage, transfer for surgery or other response and moving to recovery/care units outside the field hospital for definitive care. The large numbers of injured people reaching facilities after an air strike rapidly exhausted healthworkers and resources, and triage prioritised those at greatest need and also most likely to survive.

Within minutes, you have to have already made your decision. Quick look at each patient and quick primary assessment of their case. Some would go to operation room, others would be taken to the isolation room [black card room], another patient would be ignored who is talking loudly and has good vital signs. EA5

Triage helped health-workers deal with the ethical issues around rationing care for desperate patients given the lack of sufficient resources and skills. Operating theatre beds were very limited, especially during mass casualty events, requiring rigorous injury prioritisation.

The biggest hospital had 4 operation beds. You have 30-40 injuries. They would give orders to let only those more likely to survive in operating theatres. DA7

Non-urgent cases received first-aid to stabilise their injuries and were asked to wait, sometimes for more than a day.

My hand was injured and fractured by shelling shrapnel $[\ldots]$ I had to give first-aid to myself.... When I went to the hospital, they gave me painkillers, cooled down my situation, and sent me home $[\ldots]$. There were hundreds of injured people, [...the doctors] were too busy with other injuries .... I had to come the following day to take an x-ray of my hand. SU4

Patients with poor prognoses, for example, loss of cerebral material or pelvic bones, were separated out. All participants expressed remorse at this practice, but stressed this was the only way to handle such high demand versus low supply.

Especially in the case of massacres, we would have to take only patients whose situation needed intervention and there was a likely benefit of intervening, meaning not the patients with the 'black card'. We 
Table 2 Themes, challenges and mitigation approaches

\begin{tabular}{|c|c|c|}
\hline Themes & Primary challenges & Management/mitigation approaches \\
\hline Conflict & $\begin{array}{l}\text { Extensive/indiscriminate weapons use against } \\
\text { civilians resulting in overwhelming numbers of } \\
\text { injuries. }\end{array}$ & $\begin{array}{l}\text { Triage; deciding whose injury could benefit the most } \\
\text { from sparse supplies and time. } \\
\text { Coordinating with other hospitals to refer casualties via } \\
\text { social media. }\end{array}$ \\
\hline Targeting & $\begin{array}{l}\text { Targeted bombing of facilities requiring } \\
\text { protection for health-worker, patients and assets. } \\
\text { Extensive weapons use against civilians raising } \\
\text { constant concerns for family safety. }\end{array}$ & $\begin{array}{l}\text { Working in basement levels and using tunnels for } \\
\text { access. } \\
\text { Fortifying and hiding facilities. } \\
\text { Decentralising facilities and patients. } \\
\text { Sleeping at facilities. }\end{array}$ \\
\hline Besiegement & Severe human resource shortages. & $\begin{array}{l}\text { Telemedicine. } \\
\text { Task shifting to junior health-workers and medical } \\
\text { students. } \\
\text { Working across medical specialties. } \\
\text { Building capacities through training. }\end{array}$ \\
\hline Chronic risk & $\begin{array}{l}\text { Severe physical risk to health-workers and their } \\
\text { families. } \\
\text { Long chaotic hours in very difficult conditions. }\end{array}$ & $\begin{array}{l}\text { Feeling valued and working as part of a team. } \\
\text { Finding small joys in life and ways to maintain hope. }\end{array}$ \\
\hline
\end{tabular}

categorised black-card patients, those who were unlikely to survive [...] Even if the patient were breathing, this would be dying breathing. EA5

\section{Sterilisation, $\mathrm{X}$-rays and transfusion}

To manage frequent mass casualty events, universal precautions and transfusion standards were relaxed to rely on clinical judgement. Surgeons often had to move between patients without thoroughly sterilising operating theatres. Participants relied on chemical antiseptics instead of standard sterilising measures for instruments and consumables. Surgical instruments were sterilised using Cidex solution instead of autoclave or dry sterilisation and doctors would sometimes wipe patients with povidone-wetted cloths.

When the injury is life threatening, you would never consider sterile conditions. Your duty is to save a life, so it is possible to exceed some [red] lines. SA2

Doctors reported echography as a good alternative to $\mathrm{X}$-ray imaging, as it was more efficient and faster for some injuries, although accuracy was compromised.

Blood transfusion was done with blood typing but without cross-matching, potentially causing some haemolysis cases. Due to insufficient supplies, blood was only transfused to patients until their haemoglobin concentration reached above $80 \mathrm{~g} / \mathrm{L}$. The demand for blood donation was significant. Donation reportedly reduced in Aleppo, as many had donated multiple times.
We would provide blood until patient's haemoglobin reached $8[\mathrm{~g} / \mathrm{dl}]$. It is not necessary to be $10[\mathrm{~g} / \mathrm{dl}]$, because those who remained during the siege had donated 4-5 times until we could not find any donor. NA4

Donation remained more stable in Ghouta, though service-users indicated that poor and insufficient nutrition reduced the speed at which they could recover from blood donations or injuries.

I know cases of 18 months and 20 months old fractures and have not healed yet. This is related to lack of quantity and quality of food SU4

\section{Facility targeting and protective responses}

Participants reported health facilities being targeted by air strikes. The four main protective responses participants described were working underground, fortifying facilities, reducing visibility and dispersion.

\section{Working underground}

Participants reported that working in basement levels protected health-workers and patients from air strikes. Similarly, warehouses were maintained in underground levels to secure commodities during bombardment. Hospitals with more underground levels reportedly survived longer.

Many times while we were working, the hospital would be bombarded. The operation theatre door would 
come off or the windows would fell on us, but the [main] thing was that we worked in the lower levels, in the basement level or even lower and the building above us was 4 or 5 floors at least [...] All field hospitals should work underground. NA4

However, participants noted that during chemical attacks, for example, chlorine gas, working underground could increase the risk of injuries and fatalities because gases tended to settle and become more concentrated unless dispersed by air movements. ${ }^{46}$

\section{Fortifying facilities}

Some participants recommended fortification to prevent fragments and shrapnel injuring health-workers and patients. Sandbags were the main fortification units, or rubble-filled bags when sand was not available. Fortification was used for assets, for example, electricity generators and oxygen concentrators, which could be located in secured locations outside facilities. Security guards were identified as necessary to manage people accompanying patients, particularly when admittance was delayed due to lack of available places.

Managing those who come to the hospital with the patients helps to protect health-workers. So, there should be [security personnel] for the hospital in case someone, out of emotion and worries about a patient, bullied the health-worker NA4

While some described building fortification as crucial, others indicated that it could increase risk by making the facility more identifiable by scout aircraft. Some argued that because attacks were deliberate and fortification could not protect against advanced weaponry, fortification could make aircraft targeting easier.

Fortification proved ineffective, especially, as [...] the other side had no deterrent law or ethic, nothing to prevent them. So if you fortified the hospital you would be giving them a landmark, as no fortification would resist bunker buster bombs [...] especially barrel bombs, because this weapon is indiscriminate and depends on the sight vision of the pilot or the person who would throw the barrel [...] It was better for the buildings to be indistinct, distributed, hidden or underground. EA5

\section{Reducing visibility}

Participants reported turning off facade lighting and reducing signage to reduce facility visibility from air strikes. Ambulances were parked away from facilities and patients transported through tunnels. Media interest had to be managed carefully, as reporting could increase visibility and thus risk of air strikes. If a facility was bombed, journalists were asked not to report its name or location as this could be used to organise future attacks.

It is necessary to avoid the media taping and hide the hospital name. For example, Sakhour Hospital was attacked. When it was filmed and (the reporter) said the hospital had not been hit, the regime attacked another time... NA4

\section{Dispersing facilities}

Ghouta health-workers created a 'dispersed' hospital, with every unit (eg, departments, vaccination centres) located in a different part of the city, to minimise loss of health-workers and assets during air strikes and avoid large numbers queuing around any facility.

We created several vaccination centres and did not locate them in one place. We turned the clinical centres into vaccination centres. SG3

Patients' families and friends could pose direct and indirect risks. First, those escorting a patient to hospital, especially if armed, could react violently if their patient was not prioritised. To mitigate this, some participants reported using security guards. Second, people gathering around the hospital made it more visible to scout aircraft. Ghouta participants stated that the best way to increase patient safety was to keep them outside after surgery in external recovery points. These distant points, preferably located underground for security, replaced hospital recovery rooms.

Recovery points included big number of patients up to $100-200$ persons per one point, their existence was not seen. EA5

\section{Additional approaches}

Two health-workers reported some non-governmental organisations (NGOs) providing helpful security trainings before the siege, for example, on maintaining their safety, managing chemical attacks. Participants suggested additional trainings would be useful, in-person or via skype, on triage, war injuries management, war-related trauma treatment, stabilising injuries and damage control. Other protective practices included staying overnight at the hospital to avoid dangerous commutes, and WhatsApp group communication between hospitals and with ambulances to avoid taking the injured to newly targeted hospitals.

\section{Besiegement and mitigating resource constraints}

Crucial resources were staff, energy/fuel, internet and emergency department supplies. Limitations were mitigated through careful administration, staff capacity-building and task-shifting, and consumables stockpiling, smuggling and local production.

\section{Administration and governance}

Field hospitals generally had an administrative manager, whose role was to organise work-shifts, communicating with other hospitals (eg, referring excess patients or updating their status), and logistics (eg, sterilisation and cleaning, documentation, food storage, warehousing). Social media groups provided a convenient and quick 
platform for effective communication. However, participants reported that strong leadership and governance of medical responses were absent. Aleppo hospitals followed the Unified Medical Council, which organised medical work, but its coordination weakened as the siege progressed. Some reported dissatisfaction with leadership and coordination efforts. In Ghouta, administrative issues included corruption and poor performance.

There was not real coordination and the reason is there was not a common management. EA5

\section{Human resources}

Qualified health-workers were extremely limited. Some participants estimated density of physicians as 1 per 10 000 people. Participants described limitations across many specialties, particularly orthopaedic and neurosurgeons. Some specialties were totally absent, for example, anaesthetists, cardio-surgeons and intensive care unit (ICU) technicians.

We had a cardiologist but they killed him. They [Syrian regime] hit him with an airstrike, and now we no longer have a cardiologist. SU5

Some facilities reported sufficient numbers of nurses. As the siege progressed, however, lack of qualified healthworkers overshadowed the lack of facilities.

[Orthopaedics] were there, but their number was never sufficient. A lot of patients had to wait for 2-3 days. There was a lack in neurosurgeons, only one neurosurgery resident who was doing what he could, a lot of neuro injuries were handled by general surgeons. EA5

Mitigation primarily involved capacity-building, through shadowing, task-shifting and training. Most participants, including non-clinicians, reported working beyond their specialist academic training or experience due to the lack of qualified health-workers, which required learning from other health-workers or external training. For example, nurses delivering babies, rather than gynaecologists or midwives. Learning from other health-workers was especially important in Ghouta, as most doctors became experienced during the long-term siege.

The main benefit came from each other. Every surgeon had to attend [an operation] with a doctor from different speciality. NA4

Participants reported certain training courses as helpful. Surgeons mainly specified courses in 'war medicine' and 'damage control', whereas others mentioned safety and responding to chemical weapons. Emergency doctors took triage courses. A nurse reported studying cardiopulmonary resuscitation and advanced emergency practice. NGOs and foreign clinicians gave in-person trainings in Aleppo or Turkey before the siege or via Skype after the siege began.
In Ghouta, a medical school was established in 2016 to train doctors and nurses. It aimed to support medical students who had not completed undergraduate training because of war. A few senior clinicians provided lectures up to third year, after which students had to study on their own and take examinations in the school.

The university was [created] due to a big demand and we have a lot of hope in it. Our class is 100 students. MG1

This school helped reduce the working hours per shift.

From a year and a half on, numbers of [student doctors] increased and shifts became shorter. Regular student has a 48 hours shift per week. MG2

\section{Consumables}

Participants reported the most crucial supply constraints as energy, internet and emergency department supplies.

[There was a] complete absence of serums for a period of over 6 months, even blood bags went missing for a period of time. Now these things exist but are very scarce. SU4

Many participants described the importance of electricity. Electricity provision was essential for field hospitals to operate. Therefore, having a generator secured in a safe place and fuel barrels securely disbursed was a priority. Other important assets for protection were oxygen concentrators.

Securing a fortified place for fuel and electricity generator and oxygen generator [was crucial]. Indeed there was no regular electricity...we would rely on the generator, so if we lost it we could not get a replacement and then electricity is gone. Without it you can't do anything. NA4

Participants reported that electricity was conserved and mainly used for operating theatres, oxygen concentrators and charging light-emitting diodes (LED) batteries. Participants reported manual alternatives were more reliable than electric ones (eg, hydraulic operation beds, manual oxygen concentrators, anaesthetic devices, battery lid lights), as electricity was not stable. Similarly, echography was a practical alternative to X-rays as it required less consumables and power. Family members were requested to oxygenate patients using manual oxygen generators.

Maybe it was a mistake to rely on modern devices or electrical ones, because in a severe situation of the siege, you had very few hours of electricity, we had to do the manual thing [...]. Even the simplest things, operating tables that had electrical circuits and buttons and rely on electricity lost validity, but hydraulic tables served us until the very last moment effectively. EA5

Most participants agreed on the importance of fuel, as otherwise health-worker could not have worked, 
warehouses could not be kept cool, ambulances and other vehicles could not operate.

The most influential supply is fuel because without fuel you can't work. Everything related to oxygen generation because oxygen is the nerve [crucial element] of surgery and resuscitation... SA2

Fuel consumption was carefully controlled. Aleppo health-workers stockpiled large quantities of fuel, so its security was the main concern. In contrast, Ghouta healthworkers had to find alternative power sources and only use it as absolutely necessary. This included producing fuel from plastic or margarine by re-distillation, solar power, batteries, LED lights and adapters.

Local fuel has been produced by burning plastic and redistilling it... [We use] solar boards and adapters from 12 volts to 220 volts through batteries. SG3

Internet connections were essential, as all participants used WhatsApp or Telegram chat groups for work communications. Internet connection helped medical teams communicate and coordinate. Communication via WhatsApp groups between hospitals helped healthworkers inform each other about their status, exchanging information about available specialties, work pressures and any attacks. Internet also played a major role in contacting people outside besieged areas with status updates. Internet access was obtained from towers outside the city or via satellite.

Health-worker asserted that medical supplies used in emergency departments were most important and carefully conserved. Disposable items such as bedsheets and gauze were sterilised and reused. Gauze was used to fix cannulas to a vein.

There is re-sterilising for example, the pumps that are used in ICUs are sterilised, syringes, the gloves... We may have to sterilise some blades later if we think there is a shortage. SG3

Similarly, thoracentesis was modified from drainage by negative pressure to using a urine bag to drain pleural fluids. While participants described limited medicines and antibiotics, this was generally considered manageable as warehouses stockpiled supplies and usage could be reduced. Some items were substituted when they ran low.

We would use one substance instead of the other. For example, we would use propofol, which we had big amount of, instead of isoflourane, [needed for] more serious cases. RA6

However, anaesthetic drugs and supplies were required for surgery and consumption could not be reduced.

The main problem was anaesthetics. One can deal with wounds and reduce the consumption of antibiotics, but anaesthetics [consumption] was unavoidable. EA5
Stockpiling, smuggling and local production

Aleppo health-worker anticipated a siege and prepared by stockpiling consumables and medications that maintained them until warehouses were destroyed.

All NGOs were saying there would be a siege on Aleppo, so we tended to stockpile supplies, especially emergency supplies, serums, thoracentesis bulbs, catheters and plasters. PA3

Ghouta health-workers required alternatives, as the siege continued over 4 years, relying on smugglers and tunnels, and local production of some consumables.

The siege was [completely] imposed in middle 2014 and now we are in 2017, this has been three years now. From mid-2014 on, not a single needle entered Ghouta. Between middle 2013 and 2014 there were smugglers. [However], even tunnels would close at certain points. The area from which the tunnel starts gets besieged, you need to wait. SG3

\section{Chronic risk perceptions and responses}

Participants stressed the primary importance of safety, describing strategies and concerns in terms of safety for themselves, patients and families.

We don't have clinics in our area, only hospitals. There is no safe place for clinics. Hospitals are fortified and people go there... SU5

Participants described personal safety as a priority for health-workers, as unless they were safe they could not save others' lives. Similarly worries about family members' safety were a major distraction that reduced their effectiveness. Participants reported that assurances about their family's safety were crucial for them to focus on their professional duties. Many Aleppo participants reported their families were outside the siege, but relatives and friends were inside, while most Ghouta participants' families were inside.

This was a major reason for us to endure, that you secure for your family a safe place outside the country [...]. You feel comfortable while you are doing your duty. SA2

Participants reported not being able to work properly whenever their neighbourhoods were bombarded. Sometimes health-workers recognised injured people from their neighbourhood and would try to check on their families. Many described work as distracting them from their concerns, while others said some health-workers could not work because they needed to secure their families.

There was a serious lack of nurses and everyone was so consumed with their family that they could not come to work and transport problem would exacerbate that. EA5 
Participants described the choices they made to keep working in dangerous conditions. For example, Aleppo participants said they had known the siege was coming and that they were targeted, but chose to stay because it was an 'ethical, religious, humanitarian, and patriotic commitment'.

Regardless of my personal opinion, the only reason for me to stay in rebel-held areas was $[\ldots]$ purely a humanitarian motive. EA5

First of all, there was a lack in health-workers. Second, the humanitarian factor. Third, this is my city. If I did not defend it, how else could I be beneficial? Outside? This was my time and the golden time to participate. RA6

All participants described health facility attacks as a systematic and deliberate war tactic, with hospitals targeted multiple times with variety of weapons. What most frustrated participants was that perpetrators would probably not be held accountable. Hence, all recommended enforcing international humanitarian law.

Your being inside a hospital was more dangerous than being a fighter on a frontline [...] because you are the regime's enemy more than those who carry weapons. NA4

Participants described how the stress they experienced influenced their work, for example, not being able to come to work or requesting long breaks. All participants said their ultimate fear was not being killed but being arrested.

We sometimes received threats even from rebels themselves, they thought this hospital was only to serve them like a five-star hotel. However, this was nothing compared to our fear of the regime and that it would conquer the area and deal [horribly] with prisoners, especially with field execution. That we lived with every day. EA5

To handle fear and work pressures, participants described occupying themselves with work.

I remember one of our colleagues could not stand blood and hard work anymore so he excused himself from working and then he had a mental crisis. He was waiting for something new to happen. Things were only getting worse [...] Better to keep working even if you are not specialised in what you do. TA8

Others described maintaining a team spirit.

We lived as one family... working like a beehive. AA1

Participants described hope was a key factor that kept health-workers working during the siege. Participants reported trying to live their life as best they could, maintaining hope until the end. Most participants expressed satisfaction with whatever they had managed to do.
Under these circumstances, if you remember it now, you would be surprised how you were living it, but we lived [...]. Some people [even] got married. TA8

\section{DISCUSSION}

\section{Primary findings}

This exploratory study offers insights into how healthworkers in besieged areas in Syria continued providing care despite overwhelming workload, targeting, besiegement and safety fears. This is the first study to examine adaptations to siege and targeting in Syria from the perspective of Syrians who have remained in their country during the conflict to try to relieve suffering. As noted by Footer et al, these local health-workers have received far less research attention than have international humanitarian workers. ${ }^{48}$ Similar research examines healthcare provision in besieged Gaza, ${ }^{41}$ health and nutrition in besieged settings ${ }^{49}{ }^{50}$ and health-worker experiences in opposition-controlled areas. ${ }^{48}$

Results suggest health system strengthening implications for various actors, for example, facility/programme-managers, researchers and the international community. Results described responses to four main challenges. First, due to ongoing conflict hospitals frequently received more injured than could be treated. Second, facilities, staff and patients were at risk from targeted bombings, highlighting global non-enforcement of International Humanitarian Law. Third, resources were restricted by besiegement. Fourth, health-workers had to remain functional and resilient, despite overwhelming stresses and fears for their own and others' safety. Health-workers thus had to adapt to cope with mass casualties, try to protect themselves, their patients and their families from attacks, and mitigate resource constraints, all while maintaining their own psychological resilience.

\section{Responses to conflict}

Managing mass casualties requires rapidly removing casualties from the hazardous scene and reducing mortality in facilities. ${ }^{51}$ While the former relies on pre-hospital activities, the latter is usually achieved through triage ${ }^{52}$ After air strikes, participants' hospitals were overwhelmed with casualties and health-workers relied on triage. Despite not having needed it prior to conflict, when only emergency doctors trained in triage, besieged health-workers emphasised its importance in reducing mortality and the value of triage training they received, supporting the concept of casualty flow in disasters proposed by Frykberg. ${ }^{52}$ Mehta and others describe issues to consider in mass casualty events, including altered standards and legal and ethical bases for allocating scarce resources. ${ }^{53} 54$

The main difference in conflict responses between Aleppo and Ghouta was the greater reliance on on-the-job training and task-shifting due to the length of the siege. Participants in both areas recommended training for all health-workers in triage and war-related trauma and 
injuries management. Thus, lessons for healthcare during conflict include ensuring all health-workers are trained in triage, managing war-related traumas and personal safety. Facility and NGO managers should consider findings in stocking contingency kits with consumables used in emergency departments to stabilise injuries and reduce mortality, and updating preparedness/security plans, to ensure optimal use of health-workers and resources.

\section{Responses to targeting}

Health-workers described health facility attacks as a systematic war tactic due to failure to enforce international humanitarian law. Our findings were similar to those described by Fouad et al as 'weaponisation of healthcare', the 'purposeful use of violence to restrict or deny access to healthcare as a strategy of war'. ${ }^{14}$ While the term is not widely recognised, it appears relevant to our participants' experiences. Findings also partly overlap with International Committee of the Red Cross (ICRC) recommended protection measures for health-workers in conflicts. ${ }^{55}$ These include formulating contingency plans, protecting health facilities, securing commodities from looting and organising casualties flow. However, ICRC recommendations do not cover systematic air strikes against health facilities, and may be more appropriate for less severe conflicts. Other literature proposes documenting facility attacks more reliably and reducing biased self-reports, to discourage future perpetrators. ${ }^{18} 4856$ We found a gap in the health literature regarding evidence on operational protective measures, possibly due to the challenges in conducting such research, and more could be learnt from the military medical literature. Literature on effective means of enforcing International Humanitarian Law and enhancing accountability was also lacking.

The main difference in responses to targeting between Aleppo and Ghouta was the reliance on dispersed health facility structures in Ghouta. Lessons for other settings include fortifying key facility areas, reducing facility visibility, dispersal of personnel and resources and working underground in areas less likely to be gassed. While better protection mechanisms are arguably a practical necessity, all parties in the Syrian conflict and other conflicts should work to lift all forms of siege and collective punishment of civilians as required by international law and UN Security Council resolutions 2165 and 2191 in compliance with international humanitarian law prohibiting attacks on healthcare. UN agencies and international actors must continue to advocate for the protection of health-workers and civilians during conflicts and better mechanisms for implementing international law and UN Security Council Resolutions. Advocacy and human rights actors should continue to advocate strongly for better and monitored implementation of International Humanitarian Law and UN Security Council Resolution 2286, which obliges signatory nations to avoid targeting medical and healthcare personnel.

\section{Responses to besiegement}

Reported besiegement responses were notably different between Aleppo and Ghouta, as the first was a short-term siege for which health-workers were able to make some preparations (eg, stockpiling, resource conservation) while the protracted nature of the Ghouta siege required particularly inventive responses (eg, smuggling, local production, establishment of a medical school). Potential lessons for facility preparedness and health-worker safety planning include considering field hospitals having more than one underground floor, fortification of visible external areas, shelter for health-workers to rest, a secure generator with a sustainable fuel supply and accessible anti-chemical warfare equipment and fire extinguishers. Where feasible, facilities and resources can be dispersed over wider geographical areas to reduce severe losses of health-workers and equipment.

\section{Responses to chronic risk}

Results contribute to the literature on how health-workers persevere in dangerous working and living conditions. As in other publications, participants described serious violations of the sanctity of health by combatants during the conflict. ${ }^{148}$ Key aspects health-workers reported as strengthening their ability to cope were knowing their families were safe, feeling valued and part of a team, appreciating the everyday joys in life and finding ways to maintain hope. Lessons for agencies supporting healthworkers in similarly dangerous and challenging settings include helping families move from heavily conflict-affected areas, maintaining communication with healthworkers and providing any requested support that is feasible.

\section{Research needs}

Study findings can help in generating hypotheses for future research. The lack of preparedness and management plans described by participants may have resulted from lack of evidence in addressing mass civilian casualty events during conflicts and targeted siege. Health security research is needed to provide evidence for preparedness and protection plans, including health facility protection approaches against different weaponry, alternative power sources, reusable supplies and low-tech and/ or more energy-efficient equipment. Health services research is needed to help doctors determine the extent to which they can alter standards and potential consequences. Since research during conflict is hindered by security and poor access, simulation techniques could provide useful estimations and inferences. Health policy and systems research is needed to improve accountability and protection such as improving documentation and evidence production from conflict-affected areas and identifying ways to address the political elements necessary for effective enforcement of International Humanitarian Law. 


\section{Limitations}

Two particular limitations should be considered due to time constraints, confidentiality concerns and access issues and inferences about best practices during siege should only be made fcautiously. First, restricted topics and snowball sampling could have reduced the perspectives included (eg, women did not participate, and Ghouta participants were under-represented, due to confidentiality concerns and internet availability). Relatively fewer women health-workers worked in besieged areas and those who did were less willing than their male counterparts to participate in research, due to expressed concerns about safety and confidentiality. Potential ways to address this in future research include lengthening the data collection period to allow more time to gain the confidence of potential participants, including at least one woman interviewer, and oversampling women healthworkers. Second, reporting bias is possible. Interviewers were Syrians familiar with the socio-political context, which facilitated participant contact and discussion, but could have introduced social desirability and cultural familiarity biases (eg, particularly motivation-to-stay responses) and assumptions about interviewer neutrality. Interviewers speaking the same dialect as participants allowed opportunities to interrogate meanings and interpretations, though Twine argues that being different can also stimulate communication..$^{57}$

\section{CONCLUSIONS}

While siege settings differ, depending on length and severity of attacks against healthcare, common approaches may be used to mitigate challenges. Besieged health-workers were most affected by severe resource constraints and safety concerns while responding to overwhelming mass casualty events. Lessons for besiegement planning included consideration of capabilities to: (i) respond to conflict through in-person/ online health-worker training, for example, in triage, low-technology equipment and resource conservation, emergency response and task-shifting; (ii) mitigate targeting through facility security, for example, protection and deterrence through fortification, working underground and reducing visibility; (iii) manage besiegement through ensuring internet and electricity access; low-technology/reusable equipment; securely stockpiling fuel, medicines and supplies; and establishing alternative supply routes; and (iv) cope mentally, through feeling supported and valued despite extremely difficult circumstances.

Acknowledgements Particular thanks to all participants, who provided health services in situations of considerable risk. Thanks also to the UK government Chevening Scholarships programme for supporting NF and YD.

Contributors NF designed the study and drafted the manuscript. NF and YD collected and analysed data. NH provided supervision, contributed to data interpretation and critically revised the manuscript. All authors approved the version for submission.
Funding Chevening Scholarships provided some study funding as part of NF's and YD's MSc studies. The funder had no role in study design, data collection, analysis, interpretation or manuscript writing.

Map disclaimer The depiction of boundaries on the map(s) in this article do not imply the expression of any opinion whatsoever on the part of BMJ (or any member of its group) concerning the legal status of any country, territory, jurisdiction or area or of its authorities. The map(s) are provided without any warranty of any kind, either express or implied.

Competing interests None declared.

Patient consent for publication Not required.

Ethics approval Ethics approval was provided by the MSc Research Ethics Committee of the London School of Hygiene and Tropical Medicine in the United Kingdom (13461/RR/7786, 10874).

Provenance and peer review Not commissioned; externally peer reviewed. Data availability statement Data are available upon reasonable request.

Open access This is an open access article distributed in accordance with the Creative Commons Attribution Non Commercial (CC BY-NC 4.0) license, which permits others to distribute, remix, adapt, build upon this work non-commercially, and license their derivative works on different terms, provided the original work is properly cited, appropriate credit is given, any changes made indicated, and the use is non-commercial. See: http://creativecommons.org/licenses/by-nc/4.0/.

\section{REFERENCES}

1. The World Bank. Syrian Arab Republic, 2017. Available: http://data. worldbank.org/country/syrian-arab-republic

2. Central Bureau of Statistics. S.A.R., population and housing census 2004 (PHC 2004) Syrian Arab Republic; 2004.

3. World Population Review. Syria population, 2016. Available: http:// worldpopulationreview.com/countries/syria-population/

4. BBC. Syria: the story of the conflict, 2016. Available: http://www.bbc. co.uk/news/world-middle-east-26116868

5. Aljazeera Staff. Syria's civil war explained from the beginning, 2017. Available: http://www.aljazeera.com/news/2016/05/syria-civil-warexplained-160505084119966.html

6. Human Rights Watch. Torture Archipelago: Arbitrary Arrests, Torture, and Enforced Disappearances in Syria's Underground Prisons since March 2011 Human Rights Watch; 2012.

7. Syrian Observatory for Human Rights. About 522 thousand people were killed in 90 months since the start of the Syrian revolution in March 2011, 2018. Available: http://www.syriahr.com/en/?p=102385

8. Internation Displacemnet Monitor Centre. IDMC global report on internal displacement 2017 conflict dataset; 2017.

9. ICRC. The Geneva conventions of 12 August 1949 International Committee of the Red Cross; 1949.

10. ICRC. Summary of the Geneva conventions of 1949 and their additional protocols, 2017. Available: http://www.redcross.org/ images/MEDIA_CustomProductCatalog/m22130477_summary-ofgeneva-convention.pdf

11. World health Organisation. Attacks on health care, 2016. Available: http://www.who.int/hac/techguidance/attacksreport.pdf

12. Rubenstein LS, Bittle MD. Responsibility for protection of medical workers and facilities in armed conflict. The Lancet 2010;375:329-40.

13. Heisler M, Baker E, McKay D. Attacks on health care in syria-normalizing violations of medical neutrality? N Engl $J$ Med 2015;373:2489-91.

14. Fouad FM, Sparrow A, Tarakji A, et al. Health workers and the weaponisation of health care in Syria: a preliminary inquiry for the Lancet -American University of Beirut Commission on Syria. The Lancet 2017;390:2516-26.

15. Physicians for Human Rights. Anatomy of a crisis: a map of attacks on health care in Syria 2018; 2018.

16. Physicians for Human Rights (PHR). Anatomy of a crisis: a map of attacks on health care in Syria 2017; 2017.

17. UNOCHA. U.N.o.f.t.C.o.H.A. 2017 summary of humanitarian response plan monitoring report, 2017. Available: http://reliefweb. int/report/syrian-arab-republic/syria-2017-summary-humanitarianresponse-plan-monitoring-report-january

18. Elamein $\mathrm{M}$, Bower $\mathrm{H}$, Valderrama $\mathrm{C}$, et al. Attacks against health care in Syria, 2015-16: results from a real-time reporting tool. The Lancet 2017;390:2278-86.

19. United Nations Children's Fund UNICEF. Stop bombing schools and hospitals, says UNICEF. Available: https://www.unicef.org/media/ media_93337.html 
20. World Bank. The toll of war, 2017. Available: http://www.worldbank org/en/country/syria/publication/the-toll-of-war-the-economic-andsocial-consequences-of-the-conflict-in-syria

21. SAMS. The failure of un security Council resolution 2286 in preventing attacks on healthcare in Syria Syrian American Medical Society; 2017.

22. Siege, in Oxford English dictionary. Oxford Oxford University Press; 2018.

23. Sahloul A. The human cost of the siege in Aleppo, 2016. Available: https://www.lawfareblog.com/human-cost-siege-aleppo

24. Syria Institute. Siege Watch sixth quarterly report on besieged areas in Syria February-April 2017, 2017. Available: http://syriainstitute. org/2017/06/19/siege-watch-sixth-quarterly-report-february-april2017/

25. Misachi J. Biggest cities in Syria, 2017. Available: http://www. worldatlas.com/articles/biggest-cities-in-syria.html

26. Solomon E. Syrian aircraft strike Aleppo, rebels claim successes Reutures; 2012.

27. Reuters Staff. Syrian army says cut off all supply routes into East Aleppo Reuters; 2016.

28. Darke D, BBC. Aleppo: is besieged Syrian City facing last GASP? 2016.

29. World Health Organisation. Eastern Aleppo without any hospitals for more than 250,000 residents, 2016. Available: http://www.who.int/ mediacentre/news/statements/2016/aleppo-without-hospitals-syria/ en/

30. Mroue B. Syria rebels try to break government siege in Aleppo USA today; 2016.

31. Francis E, Perry T. Warplanes bomb Aleppo after Syrian army launches offensive Reuters; 2016.

32. Abboud S, Aljazeera. Syria's war: what went wrong in East Aleppo? 2016.

33. Reuters Staff. Syrian rebels say Aleppo truce deal Struck, to take effect shortly Reuters; 2016.

34. Aljazeera Staff. Syria rebels reach evacuation deal with government Aljazeera; 2016.

35. Violation Documentation Centre in Syria. Special report on the evacuation of civilians from East Aleppo; 2016.

36. Francis E, Barrington L. Aleppo endgame nears as evacuation resumes Reuters; 2016.

37. Alsaafin L. Syria's Eastern Ghouta: the latest casualty of war Middle East Eye; 2015.

38. OHCHR. United nations human rights office of the high commissioner, report of the independent International Commission of inquiry on the Syrian Arab Republic. Geneva; 2018.

39. MSF. Syria: doctors under siege, 2016. Available: http://www.msf. org/en/article/syria-doctors-under-siege
40. World Bank. The visible impacts of the Syrian war may only be the tip of the iceberg, 2017. Available: http://www.worldbank.org/en/news/ press-release/2017/07/18/the-visible-impacts-of-the-syrian-warmay-only-be-the-tip-of-the-iceberg

41. Smith RJ. Healthcare under siege: Geopolitics of medical service provision in the Gaza strip. Soc Sci Med 2015;146:332-40.

42. Fakhouri F. Neurosurgery under siege - Stories from Aleppo and the Syrian war: A narrative article. Asian J Neurosurg 2017;12:342.

43. MSF. Changes in medical practice in Syria: dilemmas and adaptations under the threat of attack Médecins Sans Frontières; 2016.

44. Braun V, Clarke V. Using thematic analysis in psychology. Qual Res Psychol 2006;3:77-101.

45. Tong A, Sainsbury P, Craig J. Consolidated criteria for reporting qualitative research (COREQ): a 32-item checklist for interviews and focus groups. Int J Qual Health Care 2007;19:349-57.

46. Ganesan K, Raza SK, Vijayaraghavan R. Chemical warfare agents. J Pharm Bioall Sci 2010;2:166-78.

47. White CW, Martin JG. Chlorine gas inhalation: human clinical evidence of toxicity and experience in animal models. Proc Am Thorac Soc 2010;7:257-63.

48. Footer KHA, Clouse E, Rayes D, et al. Qualitative accounts from Syrian health professionals regarding violations of the right to health, including the use of chemical weapons, in opposition-held Syria. BMJ Open 2018;8:e021096.

49. Watson F, Vespa J. The impact of a reduced and uncertain food supply in three besieged cities of Bosnia-Hercegovina. Disasters 1995;19:216-34.

50. Carballo M, Simic S, Zeric D. Health in countries torn by conflict: lessons from Sarajevo. The Lancet 1996;348:872-4.

51. Farrohknia N, Castrén M, Ehrenberg A, et al. Emergency department triage scales and their components: a systematic review of the scientific evidence. Scand J Trauma Resusc Emerg Med 2011;19:42.

52. Frykberg ER. Medical management of disasters and mass casualties from terrorist bombings: how can we cope? J Trauma 2002;53:201-12.

53. Mehta S. Disaster and mass casualty management in a hospital: how well are we prepared? J Postgrad Med 2006;52:89.

54. Hsu EB, Jenckes MW, Catlett CL, et al. Training to hospital staff to respond to a mass casualty incident. Evid Rep Technol Assess

55. ICRC. Protecting health care: key recommendations International Committee of the Red Cross; 2016.

56. Haar RJ, Risko CB, Singh S, et al. Determining the scope of attacks on health in four governorates of Syria in 2016: results of a field surveillance program. PLoS Med 2018;15:e1002559.

57. Twine FW, Warren JW. Racing research, researching race: methodological dilemmas in critical race studies. NYU Press, 2000. 